\title{
Effect of different doses of prophylactic cranial irradiation in childhood lymphoblastic leukemia on CNS relapse, late cognitive decline and learning disabilities
}

\author{
Mohamed Meshref ${ }^{*}$, Nihal ElShazly ${ }^{2}$, Mohamed Nasr ${ }^{3}$ and Rehab AbdElhai ${ }^{4}$ \\ *Correspondence: mmeshref@hotmail.com \\ 'Departments of Clinical Oncology Kasr El Eini cancer centre - Faculty of Medicine Cairo University, Al-Saray street, El-Manial, \\ Cairo 11956, Egypt. \\ ${ }^{2}$ Department of Clinical Neurophysiology- Faculty of Medicine Cairo University, Al-Saray street, El-Manial, Cairo 11956, Egypt. \\ ${ }^{3}$ Department of Psychiatry - Faculty of Medicine Cairo University, Al-Saray street, El-Manial, Cairo 11956, Egypt. \\ ${ }^{4}$ Department of Biostatistics and Community Medicine- Faculty of Medicine Cairo University, Al-Saray street, El-Manial, Cairo \\ 11956, Egypt.
}

\begin{abstract}
Backgroud: To evaluate the doses of prophylactic cranial irradiation (1800cGy/1200cGy) as regards central nervous system (CNS) relapse, late cognitive abilities and learning disabilities.

Subjects and Methods: 42 patients treated for acute lymphoblastic leukemia (ALL) and categorized to be at high risk of relapse were assessed. None of the patients had CNS disease at diagnosis. 28 patients received $1800 \mathrm{cGy}$ prophylactic cranial irradiation and 14 received $1200 \mathrm{cGy}$. All patients received intrathecal methotrexate as well as high dose methotrexate. Visual and auditory P300 studies were carried out after a mean of 4.6 years follow-up. Visual and auditory evoked potentials were done to assess visual and auditory functions at lower brain levels. Selected subscales of Wechsler Intelligence scale for children namely; similarities, vocabulary, picture completion, design, total performance, total verbal and total IQ and arithmetic abilities were applied to both subgroups.

Results: There was no difference in CNS relapse between the two groups $(\mathrm{p}=0.845)$. The $1800 \mathrm{cGy}$ group showed a significant delay of the visual P300 latency and reduction of the amplitude and delay of auditory P300 latency $(\mathrm{p}<0.001)$. In the $1200 \mathrm{cGy}$ group only the visual P300 was significantly abnormal $(\mathrm{p}<0.001)$. Psychometric studies showed no significant differences between the 1800cGy /1200cGy subgroups in total IQ and arithmetic abilities. The 1800 cGy subgroup showed significantly abnormalities in some subscales namely in similarities, total performance and picture.

Conclusions: Prophylactic whole brain irradiation if given for high risk ALL the recommended dose is $1200 \mathrm{cGy}$ due to the lower long term cognitive effect and no difference in the CNS relapse.
\end{abstract}

Key words: Acute lymphoblastic leukemia, cranial radiation, late effects, relapse

\section{Background}

Although the need of prophylactic cranial irradiation in childhood ALL protocols has been limited nowadays to high risk patients [1] still the dose of radiation has been controversial due to its late effect on the cognitive functions and learning abilities of those children. When radiation dose was decreased from 2400 cGy to 1800 cGy it reduced the neurotoxicity to an acceptable level without decreased efficacy [2]. Newer protocols have studied the decrease of the dose of radiation to 1200cGy [3]. Late effects on pituitary function and growth were also reported by most endocrinologists involved in the follow-up of the cancer survivors [4] Monitoring of therapyrelated late effects after ALL therapy in childhood has become an increasingly important area in post-therapeutic patient surveillance. Testing for specific abnormalities in the domains of memory, attention, executive function and visual-spatial skills is recommended. Event-related potentials (ERPs) are recordings of the electric field which the brain produces in fixed time-relation to an event. It uncovers steps of higher brain information processing. The later ERPs' components (the ' $\mathrm{P} 300$ ') index information processing, attention, decisions and language $[5,6]$.

The primary objective of the study was to evaluate the difference between the doses of prophylactic cranial irradiation (1800cGy vs. 1200 cGy) as regards late cognitive effects and learning abilities in both groups versus a control group using neurophysiologic and psychometric studies. The secondary objective was to evaluate the presence of CNS relapse between the 2 doses.

\section{Subjects and Methods}

Forty two patients treated from ALL in the Pediatric Oncology Unit of Kasr El Eini centre for Clinical Oncology, Cairo University between the years 2000 and 2005 were assessed in this study. The patients were all categorized as being high risk for relapse. Inclusion criteria were poor response to initial prednisone/intrathecal methotrexate

(C) 2013 Meshref et al; licensee Herbert Publications Ltd. This is an Open Access article distributed under the terms of Creative Commons Attribution License (http://creativecommons.org/licenses/by/3.0). This permits unrestricted use, distribution, and reproduction in any medium, provided the original work is properly cited. 
(prednisone-poor response [PPR]), resistance to induction therapy, Age > 12 years, hyperleucocytosis (WBC count $>$ $100,000 / \mathrm{microL}), \mathrm{T}-\mathrm{cell}$ type. None of the patients had CNS disease at diagnosis. All patients received Whole Brain Irradiation (WBI) as part of their treatment protocol.

Twenty eight patients received the first protocol which was an adaptation of the St Jude's XII ALL protocol in which patients with high risk of relapse received 1800 cGy whole brain irradiation. Fourteen patients received a second protocol which was a local departmental protocol in which the high risk patients received 1200cGy and was characterized by an intensive maintenance where blocks of systemic chemotherapy including Vincristine, Steroids and L-Asparginase was given every 3 months all through the maintenance period. All patients received intrathecal methotrexate (MTX) as well as high dose MTX. The mean total dose of systemic MTX was $12 \mathrm{gm} / \mathrm{m} 2$ in protocol $A$ and $10 \mathrm{gm} / \mathrm{m} 2$ in protocol $B$ and the mean number of intrathecal MTX injections were 12 in both protocols. The minimum follow up period between whole brain irradiation and evaluation was 3 years, mean follow-up was 4.6 years. A control group of 25 age and sex matched normal children was also assessed. All patients enrolled in both protocols who came for follow up at the time of enrolment in the study and their parents accepted to participate in the study and sign an informed consent were enrolled in the study.

\section{Psychometric studies}

Selected subscales of Wechsler Intelligence scale for children namely; similarities, vocabulary, picture completion, design, total performance, total verbal and total IQ as well as arithmetic abilities subscales were applied to both subgroups as well as the control group.

\section{Neurophysiologic studies \\ Evoked potentials}

Evoked potential studies were carried out on a digital MEB9100 Version 0.3-0.6 Neuropack $\mu$ (Nihon Kohden, Japan). Two trials for each evoked potential were recorded. The means were registered for statistical analysis.

\section{Event related potentials $(\mathrm{P} 300)$}

Auditory ERPs were carried out using the auditory oddball paradigm. Patients were instructed to raise the right hand as a reaction to the target tone but not the frequent one. The montage used was $\mathrm{Cz}$ - linked earlobes. Band pass was $0.5-70 \mathrm{~Hz}$. Stimulus intensity was adjusted at $60 \mathrm{~dB}$ above the subject's hearing threshold. Responses to 30 target and 120 non-target tones were obtained in each trial. The response to the infrequent tone consisted of negative (N100), positive, negative (N200), positive (P300) deflections. P300 latency was measured as the major positive peak after N200. P300 amplitude was measured from N200-P300 peaks. Similarly the visual ERPs were carried out using the visual oddball paradigm by means of goggles. The child received flashes of light in both eyes simultaneously. The child was instructed to raise his finger when a flash is absent unilaterally. Similar waves to those of the auditory ERPs were recorded.

\section{Visual evoked potentials (VEP's)}

Pattern reversal VEP's were carried out using 16' checker size. Stimulation was binocular at a frequency $1 \mathrm{~Hz}$. Band pass 1-300 Hz. Montage Oz-Fz. P100 wave amplitude and latency were registered.

\section{Brainstem auditory evoked potentials (BAEP's)}

BAEP's were carried out using rarefaction clicks. The stimulation was mono-aural. The montage used was $\mathrm{A} 1-\mathrm{Cz}$ and $A 2-C z$, Frequency was set at $11 \mathrm{~Hz}$ and band pass was 1-300 Hz. Stimulus intensity was adjusted at $60 \mathrm{db}$ above the patient's hearing threshold. Masking of the opposite ear was used and adjusted at $30 \mathrm{db}$ below the stimulus intensity. I-III, III-V and I-V wave interpeak latencies were automatically computed. Brain MRI and cytogenetic analysis were not routinely done due to logistic limitation at that time in our centre.

\section{Statistical method}

The data was coded and entered using the statistical package SPSS version 12. The data was summarized using descriptive statistics: mean and standard deviation for quantitative variables and number and percentage for qualitative values. Statistical differences between groups were tested using Chi Square test for qualitative variables, independent sample $t$ test (student $t$ test) for quantitative normally distributed variables and Nonparametric Mann Whitney test for quantitative variables which are not normally distributed. Correlations were done to test for linear relations between variables. $P$-values less than or equal to 0.05 were considered statistically significant.

\section{Results}

Median age at receiving irradiation was 5 years (2-13 years) and 5 years ( 2 - 12 years) in the 1200 cGy \& 1800 cGy groups respectively. Median age at examination was 8 years (5-16 years) and 10 (6-16 years) in the $1200 c G y \& 1800$ cGy groups respectively. Mean follow up period was 4.6 years (3-7 years). Male to female ratio was 1:2 (Table 1).

\section{CNS relapses}

There was $1 / 14$ patients and $1 / 28$ patients who had CNS relapse in the $1200 c G y$ and 1800 cGy groups respectively. There was no significant difference in CNS relapse between the two groups ( $p=0.854$ ) after a mean follow-up period of 4.6 years.
Neurophysiologic data
Evoked potentials
1800 cGy group
A statistically significant difference was found between 
Meshref et al. Journal of Cancer Therapeutics \& Research 2013, http://www.hoajonline.com/journals/pdf/2049-7962-2-10.pdf

Table 1. Patients' characteristics: Rdth: radiotherapy int: intrathecal, MTX : methotrexate, $\mathrm{m}^{2}$ : meter square.

\begin{tabular}{lll}
\hline Characteristic & $\begin{array}{l}\text { Group A (1200cGy) } \\
\text { no=14 }\end{array}$ & $\begin{array}{l}\text { Group B (1800cGy) } \\
\text { no=28 }\end{array}$ \\
\hline Males/Female & $4 / 10$ & $9 / 19$ \\
Median age at Rdth & $5(2-13)$ & $5(2-12)$ \\
Median age at evaluation & $8(5-16)$ & $10(6-16)$ \\
prednisone-poor response & 6 & 12 \\
resistance to induction therapy & 1 & 2 \\
WBC count > 100,000/microL & 6 & 8 \\
T Cell Immunophenotype & 4 & 7 \\
Mean no of int MTX injections & $12(6-14)$ & $12(6-14)$ \\
Mean dose of MTX received $/ \mathrm{m}^{2}$ & $12 \mathrm{gm}$ & $10 \mathrm{gm}$ \\
\hline
\end{tabular}

Table 2. Relation between P300 and Radiation dose. AP3 L: auditory P 300 latency, AP3 A: auditory P 300 amplitude, VP3 L : visual P 300 latency, VP3 A: visual P 300 amplitude.

\begin{tabular}{llllll}
\hline & Control & \multicolumn{2}{c}{ High dose /control } & \multicolumn{2}{c}{ Low dose /control } \\
\hline & Ms & Ms & p value & ms & p value \\
\hline Wave I-III & $1.82 \pm 0.24$ & $2.3 \pm 0.2$ & $<0.001$ & $2.1 \pm 0.1$ & 0.19 \\
Wave III-V & $2.04 \pm 0.44$ & $1.8 \pm 0.1$ & 0.09 & $1.9 \pm 0.13$ & 0.90 \\
Wave I-V & $3.7 \pm 0.183$ & $4.1 \pm 0.3$ & $<0.001$ & $4.0 \pm 0.2$ & 0.89 \\
VEP L & $99.8 \pm 11.07$ & $102 \pm 9.1$ & 0.55 & $99.8 \pm 3.0$ & 0.9 \\
VEP A & $17.2 \pm 7.52$ & $7.9 \pm 5.0$ & $<0.001$ & $9.4 \pm 3.2$ & 0.19 \\
AP3 L & $333.5 \pm 14.8$ & $361.6 \pm 29.3$ & $<0.001$ & $364.6 \pm 77.5$ & 0.06 \\
AP3 A & $10.8 \pm 10.8$ & $5.2 \pm 5.6$ & 0.08 & $4.9 \pm 2.1$ & 0.21 \\
VP3 L & $329.0 \pm 16.2$ & $352.9 \pm 24.5$ & $<0.001$ & $375 \pm 44.0$ & $<0.001$ \\
VP3 A & $11.0 \pm 1.5$ & $6.0 \pm 3.1$ & $<0.001$ & $4.4 \pm 1.5$ & $<0.001$ \\
\hline
\end{tabular}

Table 3. Psychometric results.

\begin{tabular}{lll}
\hline Test & $\begin{array}{l}\text { P-value } \\
\text { Group A versus Control }\end{array}$ & $\begin{array}{l}\text { P-value } \\
\text { Group B versus Control }\end{array}$ \\
\hline Total verbal & 0.456 & 0.886 \\
Total performance & 0.697 & 0.004 \\
similarities & 0.095 & 0.042 \\
Arithmetic abilities & 0.567 & 0.0756 \\
Picture compilation & 0.766 & 0.001 \\
\hline
\end{tabular}

patient and control groups regarding the auditory P300 latency $(361.6 \pm 29.3 \mathrm{~ms}$ versus $333.5 \pm 14.8 \mathrm{~ms}$ respectively, $\mathrm{p}=<0.001)$, the visual P300 latency $(352.9 \pm 24.5 \mathrm{~ms}$ versus $329.0 \pm 16.2$ ms respectively, $\mathrm{p}<0.001)$ and amplitude $(6.0 \pm 3.1 \mu \mathrm{v}$, versus $11.0 \pm 10.8 \mu \mathrm{v}$ respectively, $\mathrm{p}=<0.001)$, as well as the VEP amplitude $(7.9 \pm 5.0 \mu \mathrm{v}$ versus $17.24 \pm 7.52$ $\mu v p<0.001$ respectively) and the BAEP I-III, III-V, I-V interpeak latencies $(2.3 \pm 0.29 \mathrm{~ms}, 1.82 \pm 0.26 \mathrm{~ms}, 4.08 \pm 0.3 .6 \mathrm{~ms}$ versus $1.82 \pm 0.24 \mathrm{~ms}, 2.04 \pm 0.44 \mathrm{~ms}, 3.7 \pm 0.18 \mathrm{~ms} p=<0.001$, $0.14,<0.001$ respectively) (Table 2 ).

The auditory P300 amplitude ( $5.2 \pm 5.6 \mu \mathrm{v}$, versus $10.8 \pm$ $10.8 \mu \mathrm{v}$ respectively, $\mathrm{p}=0.08)$, the VEP latency ( $102.0 \pm 9.1$ ms versus $99.84 \pm 11.0 \mathrm{~ms}$ respectively, $\mathrm{p}=0.055$ ) showed non-significant differences between the 2 groups.

\section{0 cGy group}

A statistically significant difference was found between patient and control groups regarding the visual P300 latency $(375.0 \pm 44.0 \mathrm{~ms}$ versus $329.0 \pm 16.2 \mathrm{~ms}$ respectively, $\mathrm{p}<0.001)$ and amplitude $(4.40 \pm 1.5 \mu \mathrm{v}$, versus $11.0 \pm 1.5$ $\mu \mathrm{v}$ respectively, $\mathrm{p}=<0.001$ ), as well as the VEP amplitude (9.4 $3.2 \mu v$ versus $17.24 \pm 7.52 \mu v p=0.19$ respectively).

No significant differences was found between the 2 groups regarding the auditory P300 latency $(364.6 \pm 77.5 \mathrm{~ms}$ versus $333.5 \pm 14.8 \mathrm{~ms}$ respectively, $\mathrm{p}=0.06$ ) and amplitude $(4.9 \pm 2.1 \mu \mathrm{v}$, versus $10.8 \pm 1.08 \mu \mathrm{v}$ respectively, $p=0.21)$. The VEP latency $(99.8 \pm 3.0$ ms versus $99.84 \pm 11.0$ ms respectively, $\mathrm{p}=0.9$ ), and the BAEP I-III, III-V, I-V inter-peak latencies $(2.1 \pm 0.1 \mathrm{~ms}, 1.9 \pm 0.13 \mathrm{~ms}, 4.0 \pm 0.2 \mathrm{~ms}$ versus $1.82 \pm 0.24 \mathrm{~ms}$, $2.04 \pm 0.4 \mathrm{~ms}, 3.7 \pm 0.1 \mathrm{~ms} p=0.19,0.9,0.8$ respectively) showed non-significant differences between the 2 groups as well.

\section{Psychometric results}

Psychometric results showed no significant differences between cases and controls subgroups as regard total IQ and arithmetic abilities. There were significant differences in several subscales between controls and 1800 cGy subgroup namely in similarities, total school performance and picture compilation which were not found between controls and 1200cGy subgroup (Table 3).

\section{Discussion}

Prophylactic cranial irradiation in childhood ALL protocols is limited to high risk patients in most treatment protocols. The dose of radiation has been controversial because of its possible late effect on cognitive functions and learning abilities. The St Jude ALL Total Therapy Study XV even omitted prophylactic cranial irradiation in all $[7,8,9]$. Several Psychometric studies reported cranial irradiation at 1800 cGy to be associated with lower full scale IQ, deficits in attention, concentration and ability of sequencing and processing [10]. Some authors even recommended avoiding the strategy favoring prophylactic cranial irradiation [11].

Several previous studies reported defective cognitive functions, attention and memory deficits in children receiving different types of prophylactic protocols for ALL. Delays in the ERPs' P300 latencies and reduction of response amplitudes were mainly reported in irradiated children compared to those receiving protocols that do not include cranial irradiation $[12,13,14,15,16]$. To the best of our knowledge the comparative long-term detrimental effect of different radiation doses on the cognitive outcome in the long-term survivors of childhood ALL was not previously approached. Event related potentials' analysis showed a significantly abnormal visual P300 in both 1,800 cGys and 1,200 c Gys groups compared to the controls, the 1,800cGys group showed a further significantly abnormal auditory P300. Defective latency and amplitude of P300 indicate lowered speed of cognitive processing ,defective memory as well as impaired attention [17], which was observed in the 1800 cGy group in both higher visual and auditory functions whereas only the higher visual functions were 
impaired in the 1200 cGy group. This was reflected on some psychomotor abilities of those children especially total school performance, picture compilation and similarities in the 1800cGy group.

These findings indicate a more extensive impairment of the intellectual abilities in the subgroup receiving $1800 \mathrm{cGy}$ compared to the controls which was much less in the subgroup receiving $1200 c G y$ at no significant increased protection from CNS relapse. 1800cGy irradiation was furthermore associated with defective transmission along the auditory pathways not only at the cortical level but down to the level of the Pons and medulla as indicated by the highly significant elongation of wave I-III, III- V \& $\mathrm{I}-\mathrm{V}$ inter-peak intervals. The visual cortex and the retinocortical transmission however expressed a vulnerability to irradiation. Significantly reduced VEP amplitudes were reported in both groups denoting axonal damage within the visual pathways. This further explains the more obvious cognitive decline in the 1800 c Gys group since irradiation injury extends not only to the higher intellectual cortical functions but also to both the auditory and visual sensory processing at lower brain levels within that group. Previous studies reported sub-clinical minor CNS changes mainly involving the visual $[18,17]$ and auditory pathways [12] in the form of demeylinating lesions causing delay of the P100 wave latency and inter-latencies of waves I-III, I-IV and III-V respectively even in absence of symptoms. Radiation was accused to be the cause of white mater disturbances [20] regardless of the dose. Delays of the VEP were reported in patients who received 2400cGy [19] as well as 1800 Gys. Such delays were reported mainly in irradiated patients and not in those who received only chemotherapy $[20,21,22]$. These significant delays encouraged some authors to recommend the use of VEP latency as a tool to monitor brain radiation side effects [23] Recent studies which evaluated the cognitive outcomes of chemotherapy treatment without radiation therapy using the St Jude ALL Total Therapy Study XV showed a significantly higher risk for below-average performance specially in patients receiving higher doses of systemic chemotherapy and concluded that omitting cranial irradiation may help preserve global cognitive abilities, but treatment with chemotherapy alone is not without risks [9].

\section{Conclusion}

Prophylactic whole brain irradiation if given for high risk ALL the recommended dose is 1200 cGy due to the lower long term cognitive effect and no difference in the CNS relapse.

\section{Competing interests}

MM, NS and MN were involved in the design and conduct of the study and the interpretation of the data and the preparation of this manuscript. RA was involved in the statistical output as well as the interpretation of the data and the preparation of this manuscript. None of the other authors have any conflicts of interest to declare.
Publication history

Received: 16-May-2012 Revised: 19-Sep-2012

Re-Revised: 25-Nov-2012 Accepted: 18-Jan-2013

Published: $15-$ Feb-2013

\section{References}

1. Tsurusawa $M$, Katano $N$, Yamamoto $Y$, Hirota $T$, Koizumi S, Watanabe $A$, Takeda T, Hatae Y, Yatabe M, Mimaya J, Gushiken T, Nishi K, Anami K, Kikuta A, Kanegane H, Asami K, Nishikawa K, Sekine I, Kawano Y, Iwai A, Furuyama T, Ijichi $O$, Miyake $M$, Mugishima $H$, Fujimoto $T$, et al.: Improvement in CNS protective treatment in non-high-risk childhood acute lymphoblastic leukemia: report from the Japanese Children's Cancer and Leukemia Study Group. Med Pediatr Oncol 1999, 32:259256. | Article | PubMed

2. Halberg FE, Kramer JH, Moore IM, Wara WM, Matthay KK, Ablin AR: Prophylactic cranial irradiation dose effects on late cognitive function in children treated for acute lymphoblastic leukemia. Int $J$ Radiat Oncol Biol Phys 1992, 22:13-16. | Article I PubMed

3. Schrappe M, Reiter A, Henze G, Niemeyer C, Bode U, Kuhl J, Gadner H, Havers W, Pluss H, Kornhuber B, Zintl F, Ritter J, Urban C, Niethammer D, Riehm H: Prevention of CNS recurrence in childhood ALL: results with reduced radiotherapy combined with CNS-directed chemotherapy in four consecutive ALL-BFM trials. Klin Padiatr 1998, 210:192-199. | Article I PubMed

4. Ben Arush MW, Elhasid R: Effects of radiotherapy on the growth of children with leukemia. Pediatr Endocrinol Rev 2008, 5:785-788. | PubMed

5. Goodin DS, Squires KC, Starr. (1978) A. Long latency event related components of the auditory evoked potentials in dementia. Brain.; 101: 635-48. | Article | PubMed

6. Polich J, Ehlers CL, Otis S, Mandell AJ, Bloom FE: P300 latency reflects the degree of cognitive decline in dementing illness. Electroencephalogr Clin Neurophysiol 1986, 63:138-144. | Article | PubMed

7. Schrappe M, Reiter A, Ludwig WD, Harbott J, Zimmermann M, Hiddemann W, Niemeyer C, Henze G, Feldges A, Zintl F, Kornhuber B, Ritter J, Welte K, Gadner H, Riehm H: Improved outcome in childhood acute lymphoblastic leukemia despite reduced use of anthracyclines and cranial radiotherapy: results of trial ALL-BFM 90. GermanAustrian-Swiss ALL-BFM Study Group. Blood 2000, 95:3310-3322. | Article | PubMed

8. Roman DD, Sperduto PW: Neuropsychological effects of cranial radiation: current knowledge and future directions. Int J Radiat Oncol Biol Phys 1995, 31:983-998. | Article | PubMed

9. Conklin HM, Krull KR, Reddick WE, Pei D, Cheng C, Pui CH: Cognitive outcomes following contemporary treatment without cranial irradiation for childhood acute lymphoblastic leukemia. J Nat/ Cancer Inst 2012, 104:1386-1395. | Article | PubMed

10. Langer T, Martus P, Ottensmeier H, Hertzberg H, Beck JD, Meier W: CNS late-effects after ALL therapy in childhood. Part III: neuropsychological performance in long-term survivors of childhood ALL: impairments of concentration, attention, and memory. Med Pediatr Oncol 2002, 38:320-328. | Article | PubMed

11. Mulhern RK, Fairclough D, Ochs J: A prospective comparison of neuropsychologic performance of children surviving leukemia who received 18-Gy, 24-Gy, or no cranial irradiation. J Clin Oncol 1991, 9:1348-1356. | Article | PubMed

12. Kroczka S, Steczkowska-Klucznik M, Romaniszyn A: [Auditory evoked potentials in patients after acute children's lymphoblastic leukemia treatment]. Przegl Lek 2006, 63:1205-1209. | PubMed

13. Uberall MA, Haupt K, Meier W, Hertzberg H, Beck JD, Wenzel D: P300 abnormalities in long-time survivors of acute lymphoblastic leukemia in childhood--side effects of CNS prophylaxis? Neuropediatrics 1996, 27:130-135. | Article | PubMed

14. Moore BD, 3rd, Copeland DR, Ried H, Levy B: Neurophysiological basis of cognitive deficits in long-term survivors of childhood cancer. Arch Neurol 1992, 49:809-817. | Article | PubMed 
15. Sato T, Miyao M, Muchi H, Gunji Y, lizuka A, Yanagisawa M: P300 as indicator of effects of prophylactic cranial radiation. Pediatr Neurol 1992, 8:130-132. | Article | PubMed

16. Lahteenmaki PM, Holopainen I, Krause CM, Helenius H, Salmi TT, Heikki LA: Cognitive functions of adolescent childhood cancer survivors assessed by event-related potentials. Med Pediatr Oncol 2001, 36:442-450. | Article | PubMed

17. Ruzicka E, Tesar V, Jelinkova E, Mmerta M, Nevsimalova S, Kucerova O: Event-related potentials in evaluation of metabolic encephalopathies. Schweiz Arch Neurol Psychiatr 1993, 144:378-384. I PubMed

18. Maccolini E, Franzoni E, Vecchi V, Bravetti GO, Guidelli Guidi S: Visual evoked potentials (VEPs) in early and late CNS changes due to antileukemia treatment in children. Preliminary report. Ital J Neurol Sci 1982, 3:295-299. | Article | PubMed

19. Russo A, Schiliro G: Some aspects of neurotoxicity associated with central nervous system prophylaxis in childhood leukemia. Acta Haematol 1987, 78 Suppl 1:139-141. | Article | PubMed

20. Uberall MA, Hertzberg H, Meier W, Langer T, Beck JD, Wenzel D: Visualevoked potentials in long-term survivors of acute lymphoblastic leukemia in childhood. The German Late Effects Working Group. Neuropediatrics 1996, 27:194-196. | Article | PubMed

21. Ueberall MA, Skirl G, Strassburg HM, Wenzel D, Hertzberg $H$, Langer T, Meier W, Berger-Jones K, Huk WJ, Korinthenberg R, Beck JD: Neurophysiological findings in long-term survivors of acute lymphoblastic leukaemia in childhood treated with the BFM protocol 81 SR-A/B. Eur J Pediatr 1997, 156:727-733. | Article | PubMed

22. Muchi $H$, Satoh $T$, Yamamoto K, Karube $T$, Miyao M: Studies on the assessment of neurotoxicity in children with acute lymphoblastic leukemia. Cancer 1987, 59:891-895. | PubMed

23. Verity $C M$, Morgan $H$, Mott $M$, Oakhill A: Do visual evoked potentials detect neural damage in children treated for cancer? Dev Med Child Neurol 1990, 32:481-492. | Article | PubMed

\section{Citation:}

Meshref M, ElShazly N, Nasr M and AbdElhai R: Effect of different doses of prophylactic cranial irradiation in childhood lymphoblastic leukemia on CNS relapse, late cognitive decline and learning disabilities. journal of Cancer Therapeutics and Research 2013, 2:10. http://dx.doi.org/10.7243/2049-7962-2-10 